\title{
Communication Skills for Information System Students
}

\author{
Lech J. Janczewski \\ The University of Auckland, New Zealand
}

ech@auckland.ac.nz

\begin{abstract}
Many polls conducted in the field of Information Technology indicate that communication skills rate very high on the agenda of IT employers. At the University of Auckland, over the years we had noticed that and that formed the basis for creating a university course, which would be a sort of "total package”, exposing students to the real world of systems design. The major objective of the students who enrol in this course is to develop a real IT application, for a real business organisation, in an environment resembling the real working conditions of a systems developer. Communication skills' training is deeply embedded in the programme. Despite general opinion that the course is the most demanding, overwhelming majority of students vote each year that this course was the best they have had at the university and that they had learnt a lot.
\end{abstract}

Keywords: communication skills, information systems curriculum, information system project.

\section{Importance of Mastering Communication Skills}

Many polls conducted in the field of Information Technology indicate that communication skills rate very high on the agenda of IT employers. For example, during Y2K the results of a poll conducted in New Zealand by the Gartner Group indicated that IT managers consider communication skills as the most important for IT personnel. While formal qualifications were listed much lower. It is obvious that the abilities of presenting results of the work or opinions in a proper format are essential to a successful career. Of course, these skills must be supported by sound knowledge.

Traditional educational sector does not place adequate priority to emphasis on communication skills. The university educational process prioritises content over format. Importance of the format is rarely given any priority.

For example, the University of Auckland offers a significant number of courses (called 'papers') related to the subject of presenting knowledge such as:

Material published as part of this proceedings, either on-line or in print, is copyrighted by the author with permission granted to the publisher of Informing Science for this printing. Permission to make digital or paper copy of part or all of these works for personal or classroom use is granted without fee provided that the copies are not made or distributed for profit or commercial advantage AND that copies 1) bear this notice in full and 2) give the full citation on the first page. It is permissible to abstract these works so long as credit is given. To copy in all other cases or to republish or to post on a server or to redistribute to lists requires specific permission from the author.

$\begin{array}{ll}\text { - } & \text { Practicum in Adult Education } \\ \text { - } & \text { Culture and Education } \\ \text { - } & \text { Managing People } \\ \text { - } & \text { Communication Process } \\ \text { and many others. }\end{array}$

All these courses combined would perhaps help students to understand the psychology of audiences and methods of preparing an effective presentation but an average student cannot be expected to study so many subjects to learn effective communications skills.

That could explain why there are so many offers for training on public speaking and other communication skills. In New Zealand alone two organisations are particularly active in this field: ALC Training Pty Ltd (education division of the Pink Elephant Group) and Institute of International Research (IIR).

IIR's efforts in upgrading communication skills of its presenters are worth commenting on. IIR specialised in organizing conferences devoted to a particular, usually "hot", but narrow topic. For example: Data Communications, Information Security, E-commerce, and other business related topics. Presentations at these conferences are by invitation only and the presenters are chosen on their excellence in their field of specialisation. The presenters come mostly from the business world and they are usually not professional speakers. IIR understands that and every year it organises a special meeting for their 
speakers to help them upgrade their presentation skills. The IIR speakers who scored the highest points at their post-conference surveys usually run these sessions.

Contrary to popular opinion, the 'packaging' of the message is very important. Professor Albert Mehrabian from the University of California reports that $55 \%$ of our impact is determined by body language, posture and eyes, $38 \%$ by our voice, tone and inflection and only $7 \%$ by content. His research supports opinions about low effectiveness of remote education, which could be an important supplement to the traditional education processes, but should not be used as a replacement for it!

The reception of information is not the only problem, the presentation itself is a problem for the presenter. Mr.

Lenny Laskowski, a professional speaker, says that fear of speaking in public is the number one fear. The fear of dying is number seven.

Other tests indicate that within the first 6-8 seconds of meeting someone, we usually have formed an opinion about that individual solely by the way he/she looks. We sell (our ideas) all the time, internally and externally. Surprisingly, $94 \%$ of an executive's day is spent in communication related activities and over $50 \%$ of these involve face-to-face meetings.

Therefore Universities should help students overcome the fear of making public appearances and teach them methods of preparing a well-structured and convincing presentation.

\section{The MSIS Department Approach}

Our society has a stereotype picture of an information system specialist: it is a nerd spending most of his/her time in front of the monitor, interested only in bits, bytes and awkward looking formulas, not easy to communicate with. In other words, a typical example of "back office programmer".

On the contrary, business requirements for information systems specialists are quite the opposite. One of the most important task for an IS personnel is to find out what their clients really need. It has been proven many times before that only those systems which were developed in close cooperation between the systems analyst, programmers and the users had the chance to pass the test of time.

This implies that communication skills for IS specialists are extremely important. To meet these needs, at the Uni- versity of Auckland, for over a decade, we have been running a very successful course known as the "Information System Project". This is a course offered for the top students in their last year of studying Information Systems at the Department of Management Science and Information Systems. The main objective of the course is to develop a real computer application for a real business customer.

The foundation stone of the course was creation of an environment that would provide as close as possible an encounter with the real life of a system developer while offering the shelter of the University. To achieve this goal, the following principles were implemented:

- Majority of system development are carried out by groups of people. Hence students are asked to form development teams of 2 to 4 people.

- An effective team must be composed of people representing various skills or character traits (like chairmen, company workers, shapers, etc). We provide students with a set of tests that determine their behavioural preferences and then encourage them to form teams having a full profile in which all these traits are represented.

- Managing a successful team is a difficult task requiring a significant amount of knowledge. These knowledge are of two types:

○ Group dynamics, or functioning of group of peoples and

- Techniques of managing IS projects, time management and conducting skilful interviews.

We offer students a special training in all these skills.

- Finally, communication skills, for the reasons stated at the beginning of this paper.

As a result, we have developed a sort of "total package", exposing students to the real world of systems design, but in a controlled way. Overall statistics of the course titled "Information System Project" is presented in Fig 1.

In 2001 we have 11 teams developing information systems for business organisation operating in New Zealand, some of them of international standing, like:

- Vodafone

- CAP Gemini Ernst and Young

- Deloitte Consulting

- Royal Sun Alliance and

- Team Progress 


\section{Communication Skills}

In the past we had developed projects for companies like Microsoft, Royal New Zealand Navy, Honeywell-Bull, and IBM, etc. Apart from this a number of projects have been developed for local companies.

\begin{tabular}{|l|r|r|r|}
\hline \multicolumn{5}{|c|}{$\begin{array}{l}\text { Student } \\
\text { Year }\end{array}$} & \multicolumn{2}{c|}{ Projects } & Supervisors \\
\hline 1986 & 16 & 5 & 3 \\
\hline 1987 & 5 & 3 & 3 \\
\hline 1988 & 13 & 6 & 2 \\
\hline 1990 & 20 & 6 & 2 \\
\hline 1991 & 32 & 15 & 1 \\
\hline 1992 & 36 & 15 & 1 \\
\hline 1993 & 51 & 24 & 3 \\
\hline 1994 & 55 & 25 & 3 \\
\hline 1995 & 44 & 16 & 4 \\
\hline 1996 & 39 & 15 & 4 \\
\hline 1997 & 33 & 11 & 5 \\
\hline 1998 & 33 & 11 & 4 \\
\hline 1999 & 46 & 15 & 4 \\
\hline 2000 & 41 & 14 & 5 \\
\hline
\end{tabular}

Fig 1: Overall course statistics

The projects are real in the sense that at the end they are implemented by the sponsoring organisations. These projects are sometimes on the critical company paths where quality and adherence to the schedule is essential. Perhaps our biggest project was the one supporting the Commonwealth Games village, run in Auckland a decade ago. Examples of recent systems are: system for controlling advancement of officers for Royal New Zealand Navy, Microsoft clients' portal, WEB-driven New Zealand Coastguard membership system, etc.

\section{Communication Skills Training}

Communication skills training consist of two parts;

1. Dedicated training during special workshops

2. Preparation of formal progress reports.

At the beginning of the academic year, all students participate in an outdoor group dynamic workshop. This workshop is held in one of the tourist lodges, outside the city, on the shore of a sheltered bay connected with the Tasman Sea and at the foot of high hills. During the work- shop, their communication skills training includes the following components:

- Lecture on communication skills

- Delivery of a 5 min speech titled: "My most memorable experience"

- Delivery of an impromptu speech on a given topic

- Preparation of a presentation on a topic that was researched by a group.

Lecture on communication skills explains to students the principles of human perceptions and then shows how to structure a good public presentation. Special emphasis is placed on visual aids like whiteboard, overhead transparencies and PowerPoint. Due to the growing trend of using the last mentioned technique, a significant amount of time is spent on demonstrating proper formatting of slides, colour and font scheme, animation, etc. Students are encouraged to implement all that knowledge in their own presentations which follows the lecture.

Students usually treat the presentation very seriously. Some of these "memorable experiences" are very strong and very personal. We try disassociating from the content but it is not always possible. For instance, the story of a student who had applied for the USA's green card, which was declined, and the crushing effect it had on that person's life left a lasting impression.

After each story, students are asked to comment on the delivery method. Usually each speaker receives a very good critique, i.e. the audience points out all the positive and negative sides of each presentation. Stage fear is the predominant factor restraining the speakers. To ease that tension, these presentations are done in small groups of 5 to 7 students, and controlled by an instructor.

The regulations for impromptu speech are simple: each student from a group receives a word written on a piece of paper and must talk up to 5 min on that topic. Words from this year workshop were: FLOWER, HORSE, PICTURE, HAIR, ILLNESS, GAMBLING, PAPER, FRANCE, and PRESIDENT. One of the most interesting presentations was on "France", when a presenter talked about her impressions from her visit to Paris. The topics are distributed randomly and the distributor was not aware of the fact that that particular student had visited France. After the presentations, (which on this occasion is to assess both the content and format) a discussion is organised on the topic of how to respond to a call for delivery of an impromptu speech. Students gain a lot from that exercise, as all the 
instructors are either university lecturers or senior members of toastmaster clubs.

The last exercise on communication skills is a component of a bigger task: the students' job is to investigate a real life problem and produce a report on that subject. The topic of the investigation varies but usually it is a subject, which requires various skills. This year's topic was to produce a report to the Auckland City Council about building a new bridge, which is badly required by the citizens and businesses operating in Auckland. The students had received real regional plans, maps and preliminary reports plus detailed terms of references for producing the report. The report was delivered to the Council (the instructors acted as councillors) and two separate discussions were organised: the first on the merits of the presentation (as it would be during a real City Council meeting) and the second: a debrief, how the presentation was delivered and what were the strong and not so strong parts of the presentation.

Later, during the year, the students are able to test their skills preparing for official class presentations on their work. These class presentations are formal, in the sense they are formatted the same way as a typical managerial progress meeting. Groups are encouraged to start preparations early and test it through 'dry runs' in front of the supervisor only. These exercises are not marked and are kept very much 'down to earth'. Students have received detailed commentary on what was good or not good in their presentations. Students take note of these comments and class presentations are usually very, very good.

Interesting point is that these presentations are selfassessed. This means that students are asked to evaluate their own performance and that of the other members of the class. Their answers form the basis of the final grade for that part of the course. We have noticed that the supervisors' assessment, independently collected, follows the relative position of each team. The differences are only in the absolute values and students usually assign lower marks than the supervisors!

At the end of the course, group communication skills are tested during the presentation of the working system, to the management of the sponsoring organisation. These presentations are treated very seriously. It is almost a tradition that managing directors of the company are in attendance during these sessions. For instance, their respective directors attended all the previous final presentations of Microsoft NZ and Deloitte Consulting.
At the beginning students are very reluctant to participate in the training. However, during the year their confidence grows significantly. Their final presentations are usually on the top professional level, including animated PowerPoint slides, video clips, sound track, etc. Despite the general opinion that the course is the most demanding, an overwhelming majority of students vote each year that this course was the best they have had at the university and that they had learnt a lot.

\section{The Results}

The best place to observe the students progress is in the students project presentations. In the course of 6 months the improvements in their presentations skills are clearly visible.

Most of the first presentations are very traditional: one speaker using one overhead projector or data projector showing static texts with rudimentary animation.

But at the end, all the teams are capable of preparing and delivering of high quality professional presentations. Fig 2 depicts the entry screen of the final presentation of the best project during 1999 sponsored by the Royal New Zealand Navy. The system was aimed on managing career path of naval officers and was subsequently implemented. For their effort the team received a commendation from the commander of the NZ fleet.

Subsequent years have also produced significant results. During the 2000 final presentation, one of the teams, working for a barristers and solicitors chamber, staged a mock trial on the project. They borrowed robes and wigs and even asked a real judge to be in charge of the proceedings. Another team developed a system for helping administration of the IS resources of one of the biggest retail chains operating in New Zealand. They supported their presentation with numerous video clips to explain how the system worked and they also used the opinions of several users of the system including the owner of the chain himself.

The university receives every year a number of commendations from the industry thanking them for the job the students had done. This would not be possible without receiving good training in communication skills.

Meanwhile, an independent survey of students about the course, conducted every year indicates that:

- This is the most demanding course at the School of Business, but 


\section{Communication Skills}

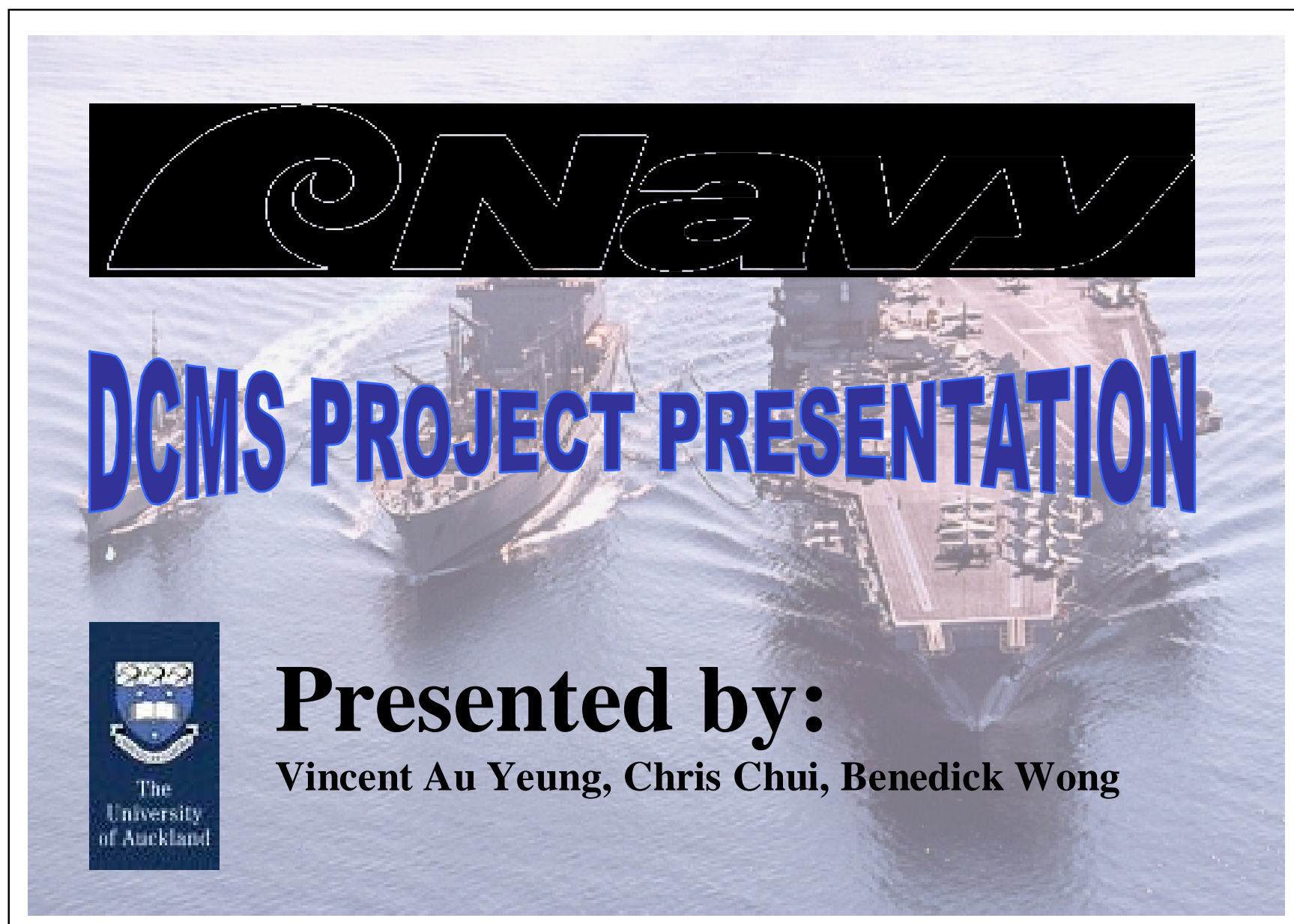

Fig 2: Entry screen of the final presentation of the RN Navy team

- This course offers the biggest learning opportunity.

\section{Biography}

\section{Conclusions}

Overall experience gained at the University of Auckland from running the "Information System Project" course, allows us to form the following conclusions related to communication skills:

- Communication skills are extremely important for anybody working in business.

- Direct lecturing on communication skills is not very effective. By 'direct lecturing' we understand a course presenting issues related to communication skills without practical exercises.

- The best method to teach communication skills is to imbed that training in an arrangement requiring frequent, assessed reporting to a specific audience.

Success of the "Information System Project" course indicates that this is the right way.
Lech Janczewski, (MEng - Warsaw, MASc - Toronto, DEng - Warsaw) has over thirty five years experience in information technology. He was the managing director of the largest IBM installation in Poland, and the project manager of the first computing center in the Niger State of Nigeria. His area of research includes management of IS resources with the special emphasis on data security and information systems investments. Dr Janczewski has written above 60 publications presented in scientific journals, conference proceedings, books and chapters in books. He is the chairperson of the New Zealand Information Security Forum and New Zealand Computer Society Auckland Region Board member. His CV was published in Marquis "Who is Who in the World 2000", "Who is Who in Science and Engineering 2000", "Who is Who in New Zealand", and many others. 